\title{
Peramalan Kejahatan Menggunakan Holt's Double Exponential Smoothing
}

\author{
Forecasting Crime using Holt's Double Exponential Smoothing
}

\section{Nurhaeni}

Program Studi Sistem Infromasi, Fakultas Sains dan Teknologi, Universitas Sari Mulia

nurhaeni030@gmail.com

\begin{abstract}
ABSTRAK
Keamanan suatu wilayah merupakan tanggungjawab bersama baik pemerintah maupun warga negara. Salah satu faktor yang mempengaruhi keamanan antara lain tercukupinya jumlah personil keamanan. Rasio penduduk per polisi belum memadai untuk mengatasi masalah tindak kejahatan di masyarakat. Data kejahatan yang dimiliki oleh kepolisian Kota Yogyakarta dari tahun 2012 hingga 2015 dapat dimanfaatkan untuk melakukan peramalan sehingga menghasilkan informasi yang dibutuhkan dalam merumuskan strategi pencegahan dan penindakan kejahatan yang efektif. Dengan demikian kepolisian dapat mengalokasikan petugas secara tepat guna sehingga perannya dalam mencegah terjadinya tindak kejahatan menjadi lebih optimal. Pola data kriminal pada umumnya memiliki trend (meningkat), sehingga pada penelitian ini bertujuan untuk meramalkan jumlah kejahatan menggunakan metode Holt's Double Exponential Smoothing. Nilai persentase kesalahan peramalan menggunakan MAPE adalah 28,1\%, sehingga akurasi hasil peramalan adalah 71,9\%. Pemilihan konstanta pemulusan $\alpha$ dan $\gamma$ sangat berpengaruh terhadap hasil peramalan tersebut. Hasil peramalan 3 bulan pertama di tahun 2016 tidak banyak berbeda dengan jumlah kejahatan di 3 bulan pertama pada tahun tahun sebelumnya.
\end{abstract}

Kata kunci: Peramalan, Double Exponential Smoothing, Kejahatan

\begin{abstract}
The security of an area is a shared responsibility with both the government and citizens. One factor that influences security among others is the ratio of population to police is not sufficient to address the problem of crime in the community. Crime data needed by the Yogyakarta City police from 2012 to 2015 can be used for forecasting so as to produce the information needed in formulating the strategies needed and effective risk management. Thus, the police can allocate appropriate officers as parties who play a role in preventing crime from becoming more optimal. The pattern of criminal data in general has a trend, increasing in this study to predict the number using the Holt double exponential smoothing method. The percentage value of forecasting errors using MAPE is $28.1 \%$, so the accuracy of forecasting results is $71.9 \%$. The selection of smoothing constants $\alpha$ and influential determine the results of forecasting. Forecasting results for the first 3 months in 2016 are no different from the amounts in the first 3 months in previous years.
\end{abstract}

Keywords: Forecasting, Double Exponential Smoothing, Crime 


\section{PENDAHULUAN}

Kriminalitas atau kejahatan adalah suatu perbuatan yang dapat mengakibatkan timbulnya masalah-masalah dan keresahan bagi kehidupan masyarakat (Abdulsyani, 1987). Keamanan suatu wilayah merupakan tanggungjawab bersama baik pemerintah maupun warga negara. Salah satu faktor yang mempengaruhi keamanan antara lain tercukupinya jumlah personil keamanan. Berdasarkan publikasi data BPS tahun 2018 (BPS, 2018), rasio penduduk per polisi di D.I. Yogyakarta pada tahun 2017 sebesar 1:374, yang artinya bahwa setiap 1 personil polisi melayani 374 penduduk. Pada tahun 2017, selang waktu tindak kejahatan (crime clock) di D.I. Yogyakarta adalah 1 jam 41 menit 24 detik, artinya setiap 1 jam 41 menit 24 detik di D.I. Yogyakarta terjadi 1 kasus tindak kejahatan.

Dengan melihat hal tersebut, sudah seharusnya kepolisian meningkatkan kinerjanya dalam mencegah dan menjaga keamanan di lingkungan masyarakat. Data kejahatan yang dimiliki oleh kepolisian ataupun Badan Pusat Statistik dapat dimanfaatkan untuk menghasilkan informasi yang dibutuhkan dalam merumuskan strategi pencegahan dan penindakan kejahatan yang efektif.

Seiring dengan kemajuan ilmu pengetahuan, telah banyak dilakukan penelitian terhadap data kejahatan dengan tujuan untuk menggali informasi lebih banyak sebagai upaya kontribusi ilmu dalam pencegahan dan penindakan kejahatan. Beberapa diantaranya adalah pengelompokkan daerah rawan kriminalitas menggunakan metode $k$ means (Hapsari and Widodo, 2017), pemodelan persentase kriminalitas dan faktor-faktor yang mempengaruhi dengan pendekatan Geographically Weighted Regression (Ratnasari Panji Anugrah, Simamora and Ratnasari, 2014), analisis dan prediksi tren kejahatan menggunakan Mahanolobis Distance dan Dynamic Time Warping (Rani and Rajasree, 2014), dan berbagai penelitian lainnya dari berbagai bidang keilmuan.

Prediksi atau peramalan adalah suatu proses memperkirakan secara sistematis tentang sesuatu yang paling mungkin terjadi di masa depan berdasarkan informasi masa lalu dan sekarang yang dimiliki, agar kesalahannya (selisih antara sesuatu yang terjadi dengan hasil perkiraan) dapat diperkecil. Peramalan tidak harus memberikan jawaban secara pasti kejadian yang akan terjadi, melainkan berusaha untuk mencari jawaban sedekat mungkin yang akan terjadi. Dengan menggunakan kumpulan data kriminal yang telah ada, kepolisian dapat meramalkan jumlah tindak kejahatan untuk dapat digunakan dalam menentukan kebijakan untuk beberapa periode tertentu.

Pada penelitian ini, peramalan jumlah kejahatan dilakukan menggunakan metode exponential smoothing. Pola data kriminalitas pada umumnya menunjukkan adanya trend (meningkat), sehingga metode Double Exponential Smoothing dari Holt dianggap cocok untuk mengolah data dengan pola tersebut. Holt mengolah data kriminal untuk meramalkan jumlah tindak kejahatan pada beberapa periode bulan ke depan.

\section{METODE}

Pada penelitian ini, data kejahatan didapatkan dari bagian kriminal umum kepolisian Kota Yogyakarta dari tahun 2012 hingga 2015 (Gambar 1). 


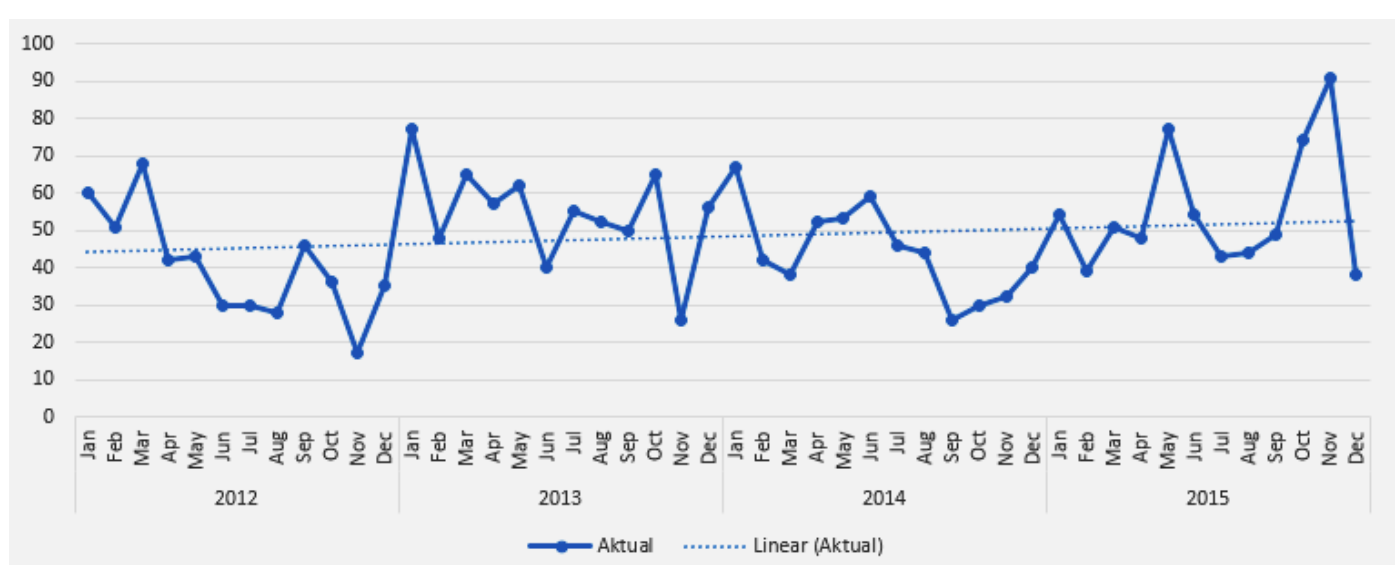

Gambar 1. Plot data time series

Berdasarkan Gambar 1, terlihat bahwa jumlah kejahatan dari tahun 2012 hingga 2015 mengalami kenaikan dan penurunan yang tidak beraturan, namun jika ditarik garis linear dari grafik tersebut menunjukkan adanya trend yang cenderung meningkat.

\section{Double Exponential Smoothing}

Metode Double Exponential Smoothing (Makridakis, Wheelwright and E.McGee, 1992) dengan dua parameter atau dikenal juga sebagai metode Holt merupakan metode pemulusan dengan dua persamaan pemulusan yaitu satu untuk stasioner $\left(\mathrm{S}_{\mathrm{t}}\right)$ dan satu untuk trend $\left(\mathrm{b}_{\mathrm{t}}\right)$.

$$
\begin{aligned}
& \mathrm{S}_{\mathrm{t}}=\alpha \mathrm{X}_{\mathrm{t}}+(1-\alpha)\left(\mathrm{S}_{\mathrm{t}-1}+\mathrm{b}_{\mathrm{t}-1}\right) \\
& \mathrm{b}_{\mathrm{t}}=\gamma\left(\mathrm{S}_{\mathrm{t}}-\mathrm{S}_{\mathrm{t}-1}\right)+(1-\gamma) \mathrm{b}_{\mathrm{t}-1} \\
& \mathrm{~F}_{\mathrm{t}+\mathrm{m}}=\left(\mathrm{S}_{\mathrm{t}}+\mathrm{b}_{\mathrm{t}} \mathrm{m}\right) \ldots \ldots \ldots \ldots \ldots \ldots \ldots \ldots \ldots \ldots \ldots \ldots \ldots \ldots \ldots \ldots
\end{aligned}
$$

dimana $0<\alpha<1,0<\gamma<1, \mathrm{X}_{\mathrm{t}}$ adalah data aktual kejahatan, dan $\mathrm{m}$ adalah jumlah periode yang ingin diramal. Sebelum memulai peramalan, perlu adanya inisialisasi data awal untuk nilai $S_{1}$ dan $b_{1}$. Nilai $S_{1}$ bisa menggunakan $S_{1}=X_{1}$, sedangkan $b_{1}$ memerlukan taksiran trend dari satu periode ke periode berikutnya.

$$
\mathrm{b}_{1}=\mathrm{X}_{2}-\mathrm{X}_{1}
$$

Ketepatan peramalan dapat diketahui dengan mengukur kesalahan persentase. Tiga ukuran tersebut yaitu Percentage Error, Mean Percentage Error, dan Mean Absolute Percentage Error.

a. Percentage Error (PE), digunakan untuk menghitung kesalahan persentase setiap periode waktu $(\mathrm{t})$.

$$
\mathrm{PE}_{\mathrm{t}}=\left(\frac{\mathrm{X}_{\mathrm{t}}-\mathrm{F}_{\mathrm{t}}}{\mathrm{X}_{\mathrm{t}}}\right)(100)
$$

b. Mean Percentage Error (MPE), didefinisikan sebagai rata - rata dari PE untuk memberikan nilai tengah kesalahan persentase.

$$
\mathrm{MPE}=\sum_{\mathrm{i}=1}^{\mathrm{n}} \mathrm{PE}_{\mathrm{i}} / \mathrm{n} \text {. }
$$

c. Mean Absolute Percentage Error (MAPE), didefinisikan sebagai nilai absolut dari PE.

$$
\mathrm{MAPE}=\sum_{\mathrm{i}=1}^{\mathrm{n}}|\mathrm{PE} \mathrm{i}| / \mathrm{n}
$$

dimana $\mathrm{n}$ adalah banyaknya periode.

\section{HASIL DAN PEMBAHASAN}

\section{A. Pemilihan Konstanta Pemulusan}


Parameter $\alpha$ dan $\gamma$ yang digunakan dalam perhitungan Holt dipilih dengan mengkombinasikan nilai dari dua parameter tersebut, kemudian dipilih kombinasi dengan nilai MAPE yang paling kecil. Rentang nilai yang dikombinasikan adalah $0<\alpha<1$ dan $0<\gamma<1$ dengan mengambil 1 angka di belakang decimal (Tabel 1). Nilai MAPE dihitung sesuai persamaan (7) dengan menggunakan data kejahatan dari periode ke-25 hingga ke-48 sebagai data uji.

Tabel 1. MAPE parameter pemulusan dengan 1 angka desimal

\begin{tabular}{ccc}
\hline $\boldsymbol{\alpha}$ & $\boldsymbol{\gamma}$ & MAPE \\
\hline 0.4 & 0.1 & 28.35 \\
0.4 & 0.2 & 28.6 \\
0.4 & 0.3 & 30.16 \\
0.4 & 0.4 & 31.12 \\
0.4 & 0.5 & 31.79 \\
0.4 & 0.6 & 32.98 \\
0.4 & 0.7 & 34.3 \\
0.4 & 0.8 & 35.66 \\
0.4 & 0.9 & 37.17 \\
\hline
\end{tabular}

Berdasarkan pada Tabel 1, terlihat bahwa nilai parameter terbaik untuk $\alpha$ adalah 0,4 dan $\gamma$ adalah 0,1 dengan nilai MAPE sebesar 28,35. Untuk lebih meminimalkan nilai MAPE, dilakukan uji kombinasi dengan mengambil 2 angka di belakang desimal terhadap nilai $\alpha$ dan $\gamma$ yang telah dipilih (Tabel 2).

Tabel 2 MAPE parameter pemulusan dengan 2 angka desimal

\begin{tabular}{ccc}
\hline $\boldsymbol{\alpha}$ & $\boldsymbol{\gamma}$ & MAPE \\
\hline 0.44 & 0.1 & 28.17 \\
0.44 & 0.11 & 28.12 \\
0.44 & 0.12 & 28.13 \\
0.44 & 0.13 & 28.16 \\
0.44 & 0.14 & 28.19 \\
0.44 & 0.15 & 28.21 \\
0.44 & 0.16 & 28.3 \\
0.44 & 0.17 & 28.39 \\
0.44 & 0.18 & 28.54 \\
0.44 & 0.19 & 28.68 \\
\hline
\end{tabular}

Berdasarkan pada Tabel 2, terlihat bahwa dengan mengambil 2 angka di belakang desimal masih didapatkan nilai MAPE yang lebih kecil yaitu 28,12 dengan parameter $\alpha$ adalah 0,44 dan $\gamma$ adalah 0,11 . Pada penelitian ini juga dilakukan penggunaan parameter dengan 3 angka di belakang desimal, namun nilai MAPE yang dihasilkan tidak mengalami penurunan yang signifikan (Tabel 3). 
Tabel 3. MAPE parameter pemulusan dengan 3 angka desimal

\begin{tabular}{ccc}
\hline $\boldsymbol{\alpha}$ & $\boldsymbol{\gamma}$ & MAPE \\
\hline 0.44 & 0.11 & 28.12 \\
0.44 & 0.111 & 28.12 \\
0.44 & 0.112 & 28.12 \\
0.44 & 0.113 & 28.11 \\
0.44 & 0.114 & 28.11 \\
0.44 & 0.115 & 28.1 \\
0.44 & 0.116 & 28.11 \\
0.44 & 0.117 & 28.11 \\
0.44 & 0.118 & 28.12 \\
0.44 & 0.119 & 28.13 \\
\hline
\end{tabular}

Berdasarkan pada Tabel 3, dapat ditentukan nilai parameter pemulusan yang digunakan untuk $\alpha$ adalah 0,44 dan $\gamma$ adalah 0,115 .

\section{B. Peramalan dengan Holt's Double Exponential Smoothing}

Proses perhitungan peramalan menggunakan metode Holt dimulai dengan memberikan inisialisasi untuk nilai pemulusan pertama, kemudian menghitung peramalan terhadap data aktual dan yang akan datang. Nilai inisialisasi untuk $S_{1}$ menggunakan data periode ke-1 $\left(\mathrm{X}_{1}\right)$ yaitu 60 , sedangkan nilai $\mathrm{b}_{1}$ ditentukan menggunakan persamaan (4) yang hasilnya adalah -9 .

Peramalan dihitung menggunakan persamaan (3) dengan terlebih dahulu melakukan perhitungan pemulusan menggunakan persamaan (1) dan persamaan (2). Hasil pemulusan dari periode ke-1 hingga ke-48 dapat dilihat pada Tabel 4.

\begin{tabular}{rrrr}
\multicolumn{4}{c}{ Tabel 4 Hasil pemulusan } \\
\hline $\mathbf{t}$ & $\mathbf{X}_{\mathbf{t}}$ & $\mathbf{S}_{\mathbf{t}}$ & $\mathbf{b}_{\mathbf{t}}$ \\
\hline 1 & 60 & 60 & -9 \\
2 & 51 & 51.00 & -9.00 \\
3 & 68 & 54.74 & -6.96 \\
4 & 42 & 44.95 & -7.41 \\
5 & 43 & 40.21 & -6.99 \\
. &. &. &. \\
. &. &. &. \\
. &. &. &. \\
43 & 43 & 52.65 & 0.67 \\
44 & 44 & 48.75 & -0.06 \\
45 & 49 & 48.84 & -0.03 \\
46 & 74 & 61.15 & 1.94 \\
47 & 91 & 76.77 & 4.13 \\
48 & 38 & 59.88 & 0.77 \\
\hline
\end{tabular}

Berdasarkan pada nilai pemulusan periode terakhir pada Tabel 4, dapat diketahui peramalan kejahatan untuk 3 bulan ke depan yaitu periode ke-49 (Januari), ke-50 
(Februari), dan ke-51 (Maret) tahun 2016 yang jumlahnya 61 pada bulan Januari dan Februari, 62 pada bulan Maret. Jumlah kejahatan ini tidak banyak berbeda dengan jumlah kejahatan di 3 bulan pertama setiap tahunnya dari 2012 hingga 2015.

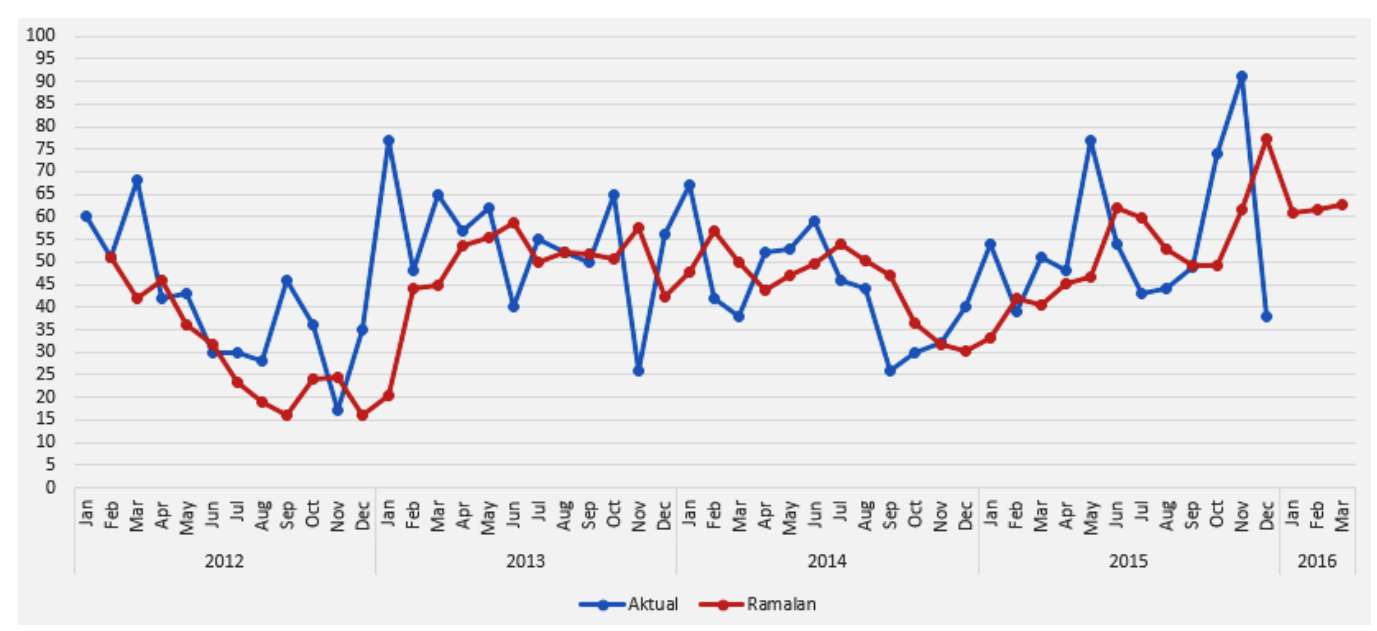

Gambar 2 Perbandingan data aktual dan hasil peramalan

Pada Gambar 2 dapat dilihat perbandingan data aktual dan hasil peramalan dari bulan Januari 2012 hingga Maret 2016 yang memiliki persentase kesalahan sebesar $28,1 \%$.

\section{KESIMPULAN}

Berdasarkan penelitian yang telah dilakukan, dapat disimpulkan bahwa peramalan jumlah kejahatan dengan metode Holt's Double Exponential Smoothing memiliki akurasi sebesar 71,9\%. Dalam hal ini, pemilihan konstanta pemulusan $\alpha$ dan $\gamma$ sangat berpengaruh terhadap hasil peramalan tersebut. Hasil peramalan 3 bulan pertama di tahun 2016 tidak banyak berbeda dengan jumlah kejahatan di 3 bulan pertama pada tahun tahun sebelumnya.

Pada penelitian selanjutnya agar menambahkan metode lain dalam menentukan nilai konstanta pemulusan $\alpha$ dan $\gamma$ sehingga dapat meningkatkan akurasi hasil peramalan. Selain itu juga perlu dilakukan penelitian lanjutan terkait pola data kejahatan karena adanya kemungkinan unsur musiman. Hal ini terlihat dari hasil peramalan setiap bulan yang tidak jauh berbeda dengan di tahun - tahun sebelumnya. Berdasarkan hal tersebut, masih perlu terus dilakukan penggalian informasi dari data kejahatan dengan memanfaatkan perkembangan ilmu pengetahuan teknologi dan informasi sehingga dapat meningkatkan upaya pencegahan dan penindakan kejahatan yang efektif.

\section{DAFTAR PUSTAKA}

Abdulsyani (1987) Sosiologi Kriminalitas. Bandung: Remadja Karya CV.

BPS (2018) Statistik Kriminal 2018, Badan Pusat Statistik. Jakarta: Badan Pusat Statistik.

Hapsari, D. P. T. and Widodo, E. (2017) 'Pengelompokan Daerah Rawan Kriminalitas di Indonesia Menggunakan Analisis K-Means Clustering', Prosiding SI MaNIs (Seminar Nasional Integrasi Matematika dan Nilai Islami), 1(1), pp. 147-153. Available at: http://conferences.uin-malang.ac.id/index.php/SIMANIS/ article/view/52.

Makridakis, S., Wheelwright, S. C. and E.McGee, V. (1992) Metode dan Aplikasi 
Peramalan Edisi Kedua.

Rani, A. and Rajasree, S. (2014) 'Crime Trend Analysis and Prediction Using Mahanolobis Distance and Dynamic Time Warping Technique', International Journal of Computer Science and Information Technologies (IJCSIT), 5(3), pp. 4131-4135. Available at: http://ijcsit.com/docs/Volume 5/vol5issue03/ijcsit20140503323.pdf.

Ratnasari Panji Anugrah, V. S., Simamora, P. A. and Ratnasari, V. (2014) 'Pemodelan Persentase Kriminalitas Dan Faktor-Faktor Yang Mempengaruhi Di Jawa Timur Dengan Pendekatan Geographically Weighted Regression (GWR)', Jurnal Sains dan Seni ITS, 3(1), pp. D18-D23. Available at: http://ejurnal.its.ac.id/index.php/sains_seni/article/view/6107. 